\title{
Tourism and mobile technology
}

\author{
Barry Brown and Matthew Chalmers \\ Computing Science, University of Glasgow, Glasgow, G12 8QQ, United Kingdom \\ barry@dcs.gla.ac.uk,matthew@dcs.gla.ac.uk
}

\begin{abstract}
While tourism presents considerable potential for the use of new mobile technologies, we currently have little understanding of how tourists organise their activities or of the problems they face. This paper presents an ethnographic study of city tourists' practices that draws out a number of implications for designing tourist technology. We describe how tourists work together in groups, collaborate around maps and guidebooks, and both 'pre-' and 'post-visit' places. Implications are drawn for three types of tourist technology: systems that explicitly support how tourists co-ordinate, electronic guidebooks and maps, and electronic tour guide applications. We discuss applications of these findings, including the Travelblog, which supports building travel-based web pages while on holiday.
\end{abstract}

\section{Introduction}

In recent years, interest in $\mathrm{CSCW}$ has expanded to include the use of technology in non-work settings, for example, the organisation of households (Hughes et al., 2000), teenagers' use of mobile phones (Grinter and Eldridge, 2001) and music listening (Brown et al., 2001). These studies have shown both the applicability of CSCW methods to these new contexts, and the relevance of findings from these contexts to core CSCW issues.

In this paper we discuss a study of city tourists, examining the problems they encounter as they move between and visit new places. Tourism has been a popular area for mobile information systems, in particular the Lancaster GUIDE system (Cheverst et al., 2000), and other PDA based systems (Abowd et al., 1997; Fesenmaier et al., 2000; Woodruff et al., 2001). Indeed, as mobile phones and other portable devices becoming more advanced, tourism is one obvious application area. However, commercial technologies in this area have had only 
limited success. There has also been little work that has studied tourism and drawn implications specifically for the design of these mobile technologies.

Here we present an ethnographic study of tourists' practices, based on a wide range of data, including observations of tourists, 'video diaries' of days out with tourists, and video recordings of tourists in public. We draw from this a number of design implications for how we could build better tourist technology. In particular, we focus on the collaborative nature of the tourist experience-the ways in which tourism is a richly social activity. The paper starts by discussing how tourists work together in groups, negotiating and arranging their activities, and co-ordinating their locations when separated. We then discuss how tourists collaborate around maps and guidebooks, focusing on the problems that tourists have in 'putting the guidebook in its place' i.e. moving from printed publications to specific attractions. Lastly, we look at how tourists both 'pre-visit' and 'postvisit' places. Tourists spend considerable time planning their activities, both before they visit and on the visit itself. However, tourists deliberately make plans that are not highly structured and specific, so that they can take advantage of changing circumstances.

We argue that systems need to better support this collaborative nature of tourism, even if this support is as simple as better links with paper maps which allow tourists to interact around a wider surface than a PDA's small screen. We also suggest how technologies could help tourists to move between the guidebook and planning their activity, such as maps that show some of the 'social structure' of cities, and guides that better support the flexible nature of tourists' plans. We are currently applying these recommendations within the City project and the Equator collaboration (www.equator.ac.uk), as we develop experimental tourist systems, extend a system to support 'co-visiting' between local and remote visitors to a museum (Brown et al., 2003), and explore theoretical issues such as the interdependence of new and old media in city life (Chalmers 2003).

\section{Tourism in the literature}

Tourism is an activity of great importance both economically and in terms of the pleasure it gives to holidaymakers worldwide. Nearly all individuals in the western world take some sort of holiday away from home every year, although the number of days differs across and within different countries. Tourism is also an activity that can divide rich and poor, through a negative or parasitical effect that damages places: 'touristification' (Apostolopoulos et al., 1996). As one would expect, there is a large body of literature that explores these issues from economic, cultural, environmental and other perspectives (Pearce, 1995; Urry, 1995; Tribe, 1999). Given this large body of existing work, one obvious question is what could CSCW offer to studying tourists. 
Previous tourism studies have noted that insufficient attention has been paid to the experience and practices of the tourist. Instead, most work has focused on the effects of tourism. Fodness and Murray comment that "detailed knowledge of the basis of actual tourist behaviour [is] lacking" (Fodness and Murry, 1997), and Aramberri argues that much tourism research "does not help to explain the nature of modern mass tourism" (Aramberri, 2001). The work that has looked in most detail at tourist practice has been the "tourist information seeking" literature (Snepenger et al., 1990; Moore et al., 1995). This literature has tended to avoid detailed qualitative description, focusing more on broad categorisations of tourist practice and questionnaire-based studies (Riley and Love, 1999).

This lack of detailed observations presents a number of problems for the design of technologies. Specifically, there is a lack of understanding of the methods tourists use to choose and arrange their various activities. This motivated our choice of ethnographic methods to look in depth at how tourists arrange their activities, rather than concentrating on the effects of tourism, as is more traditional. In doing this, our approach is similar to recent studies of museum visitors (vom Lehn et al., 2001), interactions between local people and tourists (Lee and Watson, 1993; Munro, 1998), and tourist information centres (Crabtree, 1999). In these cases a focus on the 'how' of ordinary activities, such as looking at a shared museum exhibit, can lead to findings useful for the design of technologies. Looking at tourism also presents an opportunity to explore leisure activities within CSCW and the particularly the sociality of leisure. As the growth in online gaming shows, many leisure technologies take on a new life when designed for group or social interaction. This presents opportunities for CSCW research, not least in understanding how technology can support existing rich social bonds.

\section{Studying tourism}

In this study, we combined video with conventional ethnographic observational work. We used small cameras to videotape activities in which we were participants and observers. We collected four main pieces of qualitative data. Five days were spent studying tourists in Edinburgh and Glasgow, combining observation with videoing their activities. A focus of this work was the documents that tourists used, such as maps, guidebooks, train timetables and so on. Our observations were conducted around major tourist areas: the main train stations, hostels, luxury hotels, Glasgow's main city square, and an historic street in Edinburgh called the Royal Mile. We combined these with five 'video diaries', made by accompanying tourists while sightseeing on a day in the city. We recruited groups of visitors to the city from friends and family of our university's staff. We then followed these visitors around for a day, videoing them as they chose what to do, arranged their visit and navigated their way around the city. We 
supplemented these observations with twelve interviews with tourists, which were tape recorded and later transcribed. Lastly, we conducted a five day ethnography in the Glasgow tourist information centre, collecting data from the activities of both staff and tourists asking for information ${ }^{1}$.

The data collected was diverse, but it allowed us to think about and explore what tourists do in a number of different ways, while remaining close to what tourists do. In analysing this diverse range of data we aimed to produce an ethnographic understanding of tourism; that is to say one that reflected the pressures, viewpoints and feelings of tourists as much as cataloguing their activities. In describing our analysis, we have therefore attempted to communicate our understandings of the tourist predicament, as much as describing specific fieldwork incidents.

The cities that we studied, Edinburgh and Glasgow, are the second and third most popular cities for tourists to visit in the U.K., after London (Star-UK, 2000). Summer is a particularly busy time of the year for both cities, with the Edinburgh Festival (as well as the better weather) a major tourist attraction. This influenced the type of tourists that we found. The tourists that we spoke to and studied were predominantly independent travellers, who had mostly arranged their own travel although some used the assistance of a travel agency. While the package tour market is obviously a very important part of tourism (31\% in the case of leisure visitors to the US), we focus more on tourists who arrange their activities themselves, since this group suffers more acutely from problems of organisation. While a major proportion of independent travellers are 'backpackers', young people travelling for a prolonged period of time before entering paid employment (Loker-Murphy and Pearce, 1995), independent travellers are a diverse group with a wide age range. In our case it encompassed older travellers (so called 'Peter Pan' travellers), those on short city breaks, and travellers with a specific sporting interest-most prominently hill-walking and golf.

In thinking about what tourists do, we found it useful to consider tourist 'problems' and 'solutions'. One example from the fieldwork is that tourists often need to use public transport to get between places. To do this they need to solve a number of practical problems, such as finding where bus stops are, finding out which bus to get, and so on. Discussing tourist activity in this way gave us a focus on practical activities: the most important part of tourism for the purposes of designing new tourism systems. This emphasises the decisions that tourists make and the information they use to make these decisions. However, we must be careful not to become too focused on utility, as tourists' problems are not like work problems. Solving these problems is actually part of the enjoyment of being

1 One additional source of data was our own experiences as tourists during the time we conducted the study. While we did not collect this data as systematically as the other sources, field notes were taken during four tourist trips by the authors. 
a tourist. In deciding what to do and how to do it, a tourist learns about the place they are visiting. As the old saying goes: "getting there is half the fun".

We discuss our fieldwork and its implications in three sections. First is a general discussion of the problems which tourists face, and the decisions that tourists have to make. Second, we look at the solutions tourists use and in particular the resources that they bring to bear on these problems. This includes working with others, guidebooks, maps and plans. Lastly, we discuss the possibilities for the design of new tourist technologies, and outline two prototype systems informed by our studies and currently under development.

\section{Tourist problems}

We start by outlining the problems which tourists face on their holidays. Although these observations come from our fieldwork, we will refrain from discussing the fieldwork in depth until the next section. The first, seemingly straightforward, problem which tourists face in an unfamiliar place is what to do. Unlike work, where tasks are often determined (in part) by an overall goal or by other people's plans, tourism is much more open-ended. Tourism encompasses a broad range of activities such as sightseeing, relaxing, shopping, visiting friends and visiting family. Indeed, since tourism can be part of business travel, the boundary between work and leisure is often blurred. Yet whatever tourists do, they must at least make some sort of decision about what to do, often in advance. This decision must take into account the time it takes to get to different places, as well as balancing the attraction of different sites. Even when one arrives at a tourist 'attraction' this problem reappears at a different scale, e,g. which parts of a large museum to visit?

Along with the question of what to do, tourists need to work out how they are going to do these different activities. When one reaches a tourist site one has to be careful about how one acts, since behavioural norms can be different in different countries. Ignorance about local customs is an oft mocked feature of tourists. Even straightforward activities such as buying goods can be organised differently in different countries, compounded with the problems of working with a new currency, and avoiding being exploited, or just 'looking stupid'.

Along with what and how, tourists have to manage when they do different activities. Tourism is usually constrained in time, because of the need to return home. Time is also a problem in that tourists work with organisations that provide services: opening times must be co-ordinated with the times of public transport, such as trains or buses. This is compounded by the 'pre-booking problem'. Many facilities require pre-booking, so decisions need to be made before one has been to a place.

These two problems in turn interact with our third tourist problem: finding where things are. In visiting a city many of the attractions are distributed around 
the city. There is therefore a need to avoid spending too much time travelling between places, understand what one might see and do along the way, and group together attractions which are close together. In doing so tourists must also navigate public transport, often with limited information, or unfamiliar road systems.

Lastly, an important part of a holiday is sharing that holiday with others who are at home. Although the tourist fascination with taking photos or videos has been often criticised (Bourdieu, 1990), it displays how visitors are not isolated individuals but are part of a social group. Tourists record and represent experiences in the form of photos and stories, to remind themselves of the visit and to share with others after they return home. This is a valuable part of tourism. The most successful tourist technology is the camera, specifically designed for this 'taking the visit back home'. The popularity of Internet cafés for tourists also suggests that email sent back home is becoming a significant part of the tourist experience.

\section{Tourist solutions}

We emphasise again that these 'problems' are not a negative part of tourism. Travelling and finding out where to go is part of the very enjoyment of tourism. Tourism transforms what might seem mundane activities into something enjoyable or even romantic. Train journeys, for example, are a common resource for the travel writer, and bus and underground travel can have their own pleasures (such as the smell of the train's tires in the Parisian metro, or the electronic sounds of the Tokyo subway). Particularly in city visits, walking between places is an important part of being in a place, with 'street life' being one of the easiest ways to access the natural life of locals (chapter vii, De Certeau, 1984). These pleasures are a whimsical yet crucial part of the enjoyment of tourism.

So, in solving these problems tourists are not simply looking for some optimal solution. Instead, solving these problems is part of the enjoyment of the experience; finding a nice café or reading a map, for example, is enjoyable in itself. Accordingly, the solutions that tourists have to these problems are often finely tuned to both the problem and the enjoyment of working through the problem.

\section{Sharing the visit with others}

One method that tourists use to solve their problems is sharing the visit with other tourists. Tourism is very much a social activity. A tourist generally travels with others, e.g. as part of a family group, and statistics from the US show that $79 \%$ of leisure visits involve groups of two or more (USDTI, 1999). Since leisure travel is predominantly group-based, there is considerable intra-group interaction and collaboration. For example, Figure 1 shows some frames taken from a video 
of two tourists who have just arrived at Edinburgh's main train station. The first tourist holds an "A to Z" street guide to Edinburgh, and is looking through it. While the second tourist glances around the railway station, the first tourist finds the correct page of the map. Then the second tourist takes out her glasses to look

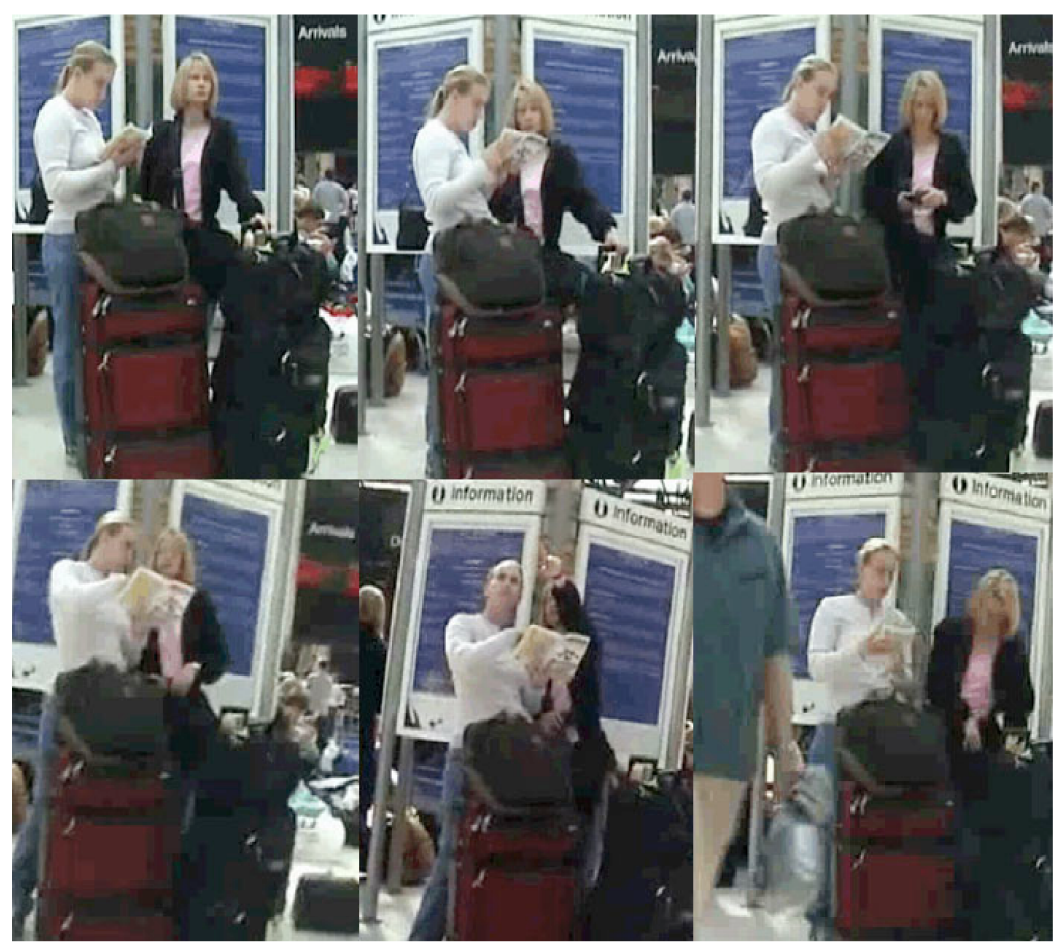

at the map, glances at the map and then points at an exit sign in the train station that names the street to which the exit leads. They then give the street guide a last look, pick up their bags and leave the station.

\section{Figure 1: Tourists at a train station}

Even in this simple excerpt one can see a division of labour between the two tourists. The second tourist looks around the station to find the exit, while the first tourist tries to find the correct page on the map. She holds the map so as to make both the map and her progress in using it available to her companion. On finding the station, she describes the location of the station to her friend, and the friend adds the name of the street reached via the exit. With these two items of information, they now know where they are on the map, where the exit will take them and how to proceed to their destination. Reading the map is done here in such a way that it can be 'checked' by the first tourist's companion. If she makes a mistake (which is easy to do), or if they later find themselves lost, the companion can intervene. The job of remembering the route is thus shared by the two tourists. Together they use the environment to move between the map and a course of activity. The sign in the station is used to link the map with where the station exit leads. 
Along with these collaborative advantages of working together, visiting with others is not without its own overheads. With the collaborative 'working out' in this clip there is also an implicit negotiation going on. The two tourists are deciding what they are going to do as well as how. Visiting with others involves considerable co-ordination in this way. The desire to visit different attractions, or simply to see different museum exhibits, means that tourist groups often split up and then need to co-ordinate getting back together. This can present considerable challenges since tourists are highly mobile. It is in these situations that mobile phones become a useful tool, in that calls can be made between individuals or sub-groups ${ }^{2}$. A more local form of this co-ordination problem also takes place in particular sites where individuals go to different rooms, or different exhibits, and they need to locate their travelling companions. This is particularly the case for tourists with children, since children sometimes run off, and must be carefully watched to see that they come to no harm. In the incidents we observed, mothers spent considerable time shepherding children around museums, in particular, collecting all the children together before leaving the museum. For these parents a large part of their holiday was 'managing' the group and making sure that nobody got lost.

A second way in which visits are shared is through meeting other tourists (Loker-Murphy et al., 1995). The standard jokes about holiday romances displays something of the way that meeting other people is an integral part of many tourist experiences. In part, these opportunities come from the lowered barriers to social contact. Individuals are 'on holiday' from many of their home commitments. The facilities that tourists use, such as hostels, trains and buses, also can also afford social contact. One reason behind these social contacts, and certainly a common conversation topic, is the exchange of stories and advice on where to go and what to visit. In our interviews this advice was given great value, greater even than information given by guidebooks or tourist information staff. This 'word of mouth' sharing allows tourists to exchange information on sites that have changed, as well as informal information about different places and facilities, such as their friendliness. However, these meetings and conversations are not just forums for the exchange of information. They provide a 'ticket to talk' (Sacks, 1992) with other tourists: an excuse and a basis for more general conversation. The social contact that these conversations initiate may be of more value than the exchange of information - they are as much platforms for establishing other (possibly temporary) social bonds, or simply enjoying the company of new people.

2 With many mobile phone charging systems these are the most expensive calls possible with the cost as high as two international calls to connect a call between two foreign mobile-phones in the same country. 


\section{Putting guidebooks in their place}

A second way tourists solve their problems is the use of published information. The two most quintessential tourist publications are the guidebook and the map. These are often used in combination when tourists navigate and find out about what to do in different places and how to get between them. While both have been subject to computerisation, this has had only limited success. For example, we did not observe any use of digital maps or guidebooks in our observations. In part, this limited success can be put down to a lack of knowledge about how maps and guidebooks are actually used by tourists. Studying the use of these conventional paper publications can reveal to us some of the advantages of paper publications and how to better design their digital equivalents.

Guidebooks come in many different forms, from free handouts to Michelin and Baedeker guides. One reason why guidebooks are so useful to tourists is that they catalogue, in a structured and relatively standardised form, relevant aspects of the places that tourists visit. They list accommodation (with phone numbers), attractions (with opening times), recommended bars and restaurants, and so on. This standardisation can make strange places feel considerably safer to tourists by reducing their uncertainty.

Guidebooks also offer short 'guides to action', highlighting differences in everyday activities that might cause embarrassment. In use, however, this information needs considerable interpretation-guidebooks need to be 'put in their place'. What the guidebook says has to be combined with other information, in particular information on maps, or advice from locals. We frequently found tourists holding a map and a guidebook, and using these in combination. In particular, guidebooks were collaborative artefacts, conversation would take place around the guidebook with tourists pointing at the guidebook, and then pointing either at a map or in a direction, so as to link together the establishments being discussed with their position.

Indeed, finding something from a guidebook can be a challenge even when it is very close by. In the following extract (figure 2), a group of tourists are looking for a particular historic house. The confusion of the tourists here is apparent, and the volunteered assistance of the researcher (B) is only partially helpful. The conversation takes place here around a map contained in a guidebook and a page of text describing different attractions. The tourists talk about an old house they are looking for, point at its location on a map in the guidebook and then attempt to find that location on the street. As can be seen from this extract the guidebook is a rich collaborative artefact-it supports a group working around the book, pointing at different items and solving their problems together. Yet even though they are only a few metres from the house, navigating with the map and the guidebook together causes some confusion. A GPS positioning system here would have been of little help; the tourists' problem is in moving from the guidebook to the street they are on. Although they find the house on a map, its 
street name ("Lawnmarket") is not enough for them to find the house without some work. The street they are on is labelled "Lawnmarket", it is often simply called "the High Street" by locals since it is a continuation of that street. Confusingly, "Castle Hill Street" is very close by too:

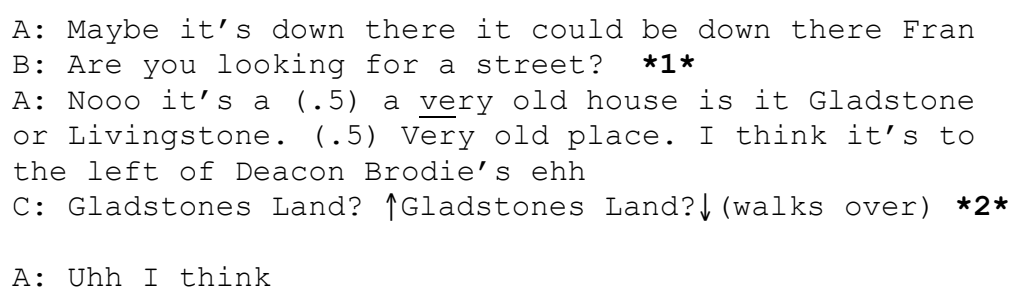

Figure 2: Tourist using a guidebook to find a historic house

The tourists go through a number of descriptions of where the house is and what it is like to help them find it ("to the left of Deacon Brodies", "very old", "six story", "477") with eventually the age helping them to find the house "its probably the old one" (on this sort of activity see (Schlegoff, 1972)). These descriptions help the tourists to find the house, along with informing them about what they are visiting. Even with a map, a guidebook, and the assistance of a local, the tourists need to work the guidebook to 'place' the old house on the street they are actually on, and overcome some of the confusions of streets which change name, the difference between how a street is named on a map and a name that locals use. In this way, tourists take the information held in guidebooks and combine this with information they find from particular places, such as street 


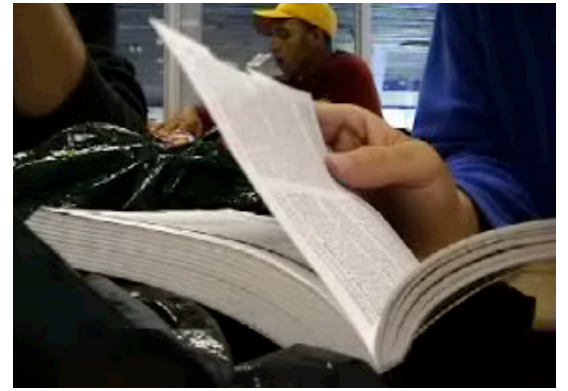

Figure 3: A tourist reads a guidebook but keeps his finger on another page, so that he can quickly go back.

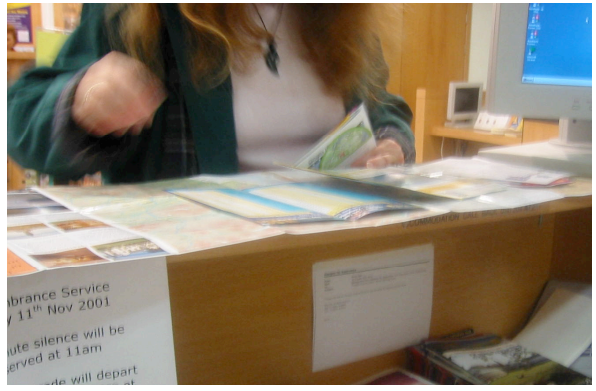

Figure 4: Multiple publications are laid out on the counter of the Tourist Information Centre

names or train timetables in a railway station. This is how guidebooks are 'put in their place'.

In designing technologies for tourism we should also pay attention to a second aspect of guidebooks: their physical form. The photographs attached to the last extract, and Figures 3 and 4, all show how the physical form of the guidebook plays a role in its use. Pages in guidebooks can be easily bookmarked by placing one's fingers into the pages at multiple points in the book, and opening the book on a particular page (Figure 3). While this might seem a trivial operation, it supports jumping between different pages quickly so as to compare and combine information, with the fingers acting as bookmarks. This is important, since much of the work of tourists is this very comparison and combination-as in combining information on maps with descriptions. Different publications can also be arranged so that they are in the visual field at the same time. Conversations over accommodation at the TIC would often take place with the guides laid across the serving desk, with staff helping visitors through the guides to show where different sorts of accommodation in the city were (Figure 4). In this way, the format of the paper guide allowed both staff and visitor to interact around the guide (see also (Sellen and Harper, 2001)).

\section{Moving with maps}

The second popular tourist publication that we saw widely used in our observations was the map. Maps have of course been a well-researched artefact in fields as widespread as cognitive psychology and cultural studies. The specific topic of way-finding has been explored in depth (MacEachren, 1995; Hunt and Waller, 1999). One finding from these studies is that map users are significantly better at tasks that involve configuration information (such as how far one landmark is from another) than those without maps, sometimes better even than local people with years of knowledge of a place (Lloyd, 1989).

However, perhaps surprisingly, there is little work that has examined the in-situ, non-experimental use of maps. As Cornell and Heth argue, there is a need 
for work which studies "humans navigating real world routes" (Cornell and Heth, 2000) since little work has looked at the 'naturalistic' use of maps: how they are used in situ without an experimental task ${ }^{3}$.

Looking at our data on map use shows many different uses of maps, which differs from the notion of maps as a straightforward tool for planning a route between points $\mathrm{A}$ and $\mathrm{B}$. We observed tourists using maps in situations where they did not know exactly where they are going, but only had an idea of a particular area that they were heading towards. This was usually because they believed that they would find something interesting in that area, although they had no specific attraction in mind. Alternatively, tourists used maps to go towards a specific type of attraction, such as a café, but with no specific café in mind - they would head towards a street where they thought there would be cafés.

Tourists also often only had a rough idea of where they were, and would use a map to locate or orient themselves so as to head in a 'roughly correct' direction, rather than along a specific route. So, in using a map, tourists might not know where they were, might have little idea about their orientation, might not know where they were going, and might even be unsure about what they were looking for. So, map use is often less about explicit route planning and more about wandering a city in a 'roughly correct' manner. The routes that tourists used were more directional than specific, with tourists frequently stopping en route, using the map to find the direction to walk in, and then setting off again.

A second feature of map use is their combination with guidebooks. A key aspect of this is how tourists combine characteristics and geography in an attempt to simultaneously solve the problems of where things are and what things there are. One way of doing this that we observed exploits the 'social zoning' of cities. As any frequent traveller will know, one of the most effective ways to find a restaurant in an unfamiliar city is to simply wander around a central area. Although by no means a perfect way of finding particular amenities, walking around exploits the tendency of certain facilities (such as bars and restaurants) to be clustered in particular area ${ }^{4}$. In this way, one can also judge establishments by their appearance and menu, as one walks past.

These 'clusters' are exploited in tourists' use of maps. When choosing where to go to, it is often safer to pick an area with more than one potential facility. We observed tourists heading towards a 'restaurant zone' of a city, often with one restaurant in mind, but with the flexibility to go elsewhere should that restaurant prove to be busy or unsuitable. By combining maps and guidebooks, tourists can look for 'clusters' of facilities in particular areas and go towards these particular areas rather than (or in addition to) heading towards a specific establishment.

This is not to say that maps are never used for working out how to get to specific places or attractions, but our observations showed some of the problems

\footnotetext{
3 Alternatively, in CSCW, maps have also been discussed as resources for guiding activity (Schmidt, 1997).

${ }^{4}$ Although this is a tendency of smaller or denser cities: Manhattan rather than Los Angeles.
} 
that tourists had in doing this. Following a route on a map involves considerable interpretation as one moves around a city (Smith, 1996). A tourist has to link between the map and what they see of streets and landmarks. Our observations showed many tourists pointing or turning their bodies towards different places to help them work out where to go (Figures 5 and 6).

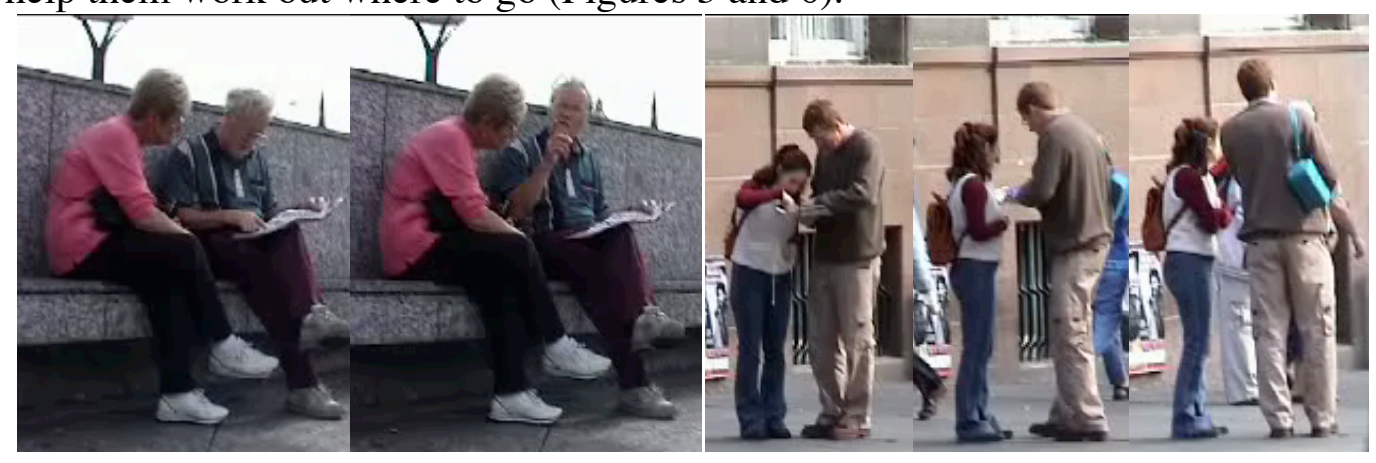

Figure 5: tourists point at a place and a map to link them together
Figure 6: two tourists turn around to orientate themselves

Even though the places that these tourists were going to were not visible, they turned so as to see where they were going. This is our embodied sense of position and location (Jonsson, 2002), how we see and understand where things are in and beyond our visual field. Indeed, when staff in the tourist information centre gave directions, they combined two different methods. One set of directions was given by drawing a line on a map - a portable and abstract version that can be used by a tourist to find their destination. Staff combined this with 'showing' in physical space where the destination was and how to get there: saying "it's behind us on Argyle Street" while using an arm movement to point in a specific direction.

A last point about maps' use concerns how they are frequently read in advance of getting to the place the map describes. This was a common use of maps we observed. Indeed, this pointed us towards a much-neglected aspect of using maps: their educational function. A major aim of using a map is to learn about a place sufficiently that one can get around without using a map, learning about a place by looking at where the streets go, the names of the streets and potential landmarks. We observed one tourist who spent over twenty minutes at a Glasgow train station reading a map of a popular mountain walk. In looking at the map, this tourist was learning about his walk. While not explicitly finding his way, he was learning about things that would help him when on the walk, such as the distances between places and what landmarks and sights there are around the area. When we use maps in situ by the process of travelling around, we are also learning about sites and streets in such a way that if we return we will have more idea of our location and how to get around. If, technologically, we just support wayfinding then we will neglect this crucial function. Maps provide an overview and allow us to fit our observations and our travelling together. 


\section{Pre- and Post-visiting}

The last solution we will discuss concerns how tourists use 'pre-visiting' and 'post-visiting' of places to manage their holiday. While our focus so far has been on the visit, considerable work is done by tourists before they travel, in gathering information and planning what to do. Tourists pre-visit a place by reading about it before they go there. Through arranging information and reading about a place before travelling, a tourist can do some of the organising activity for the holiday before the holiday. As with many of the other solutions outlined above, previsiting is not only practical; it is enjoyable. It extends the excitement of the holiday and builds anticipation as well as giving the visitor some sort of idea of what they are visiting before they get there.

Pre-visiting also happens while on the holiday itself, with tourists gathering information about places and planning what they are going to do. One important aspect of tourist planning is that it is 'satisficing' (Simon, 1955), in that plans are 'good enough' rather than detailed plans of activity. Indeed, tourists' plans are often deliberately ambiguous so that they can take into account future contingencies. As Suchman argues, plans often do not determine behaviour but rather are used flexibly in deciding what to do (Suchman, 1987). This acknowledges that decisions are often easier to make when one is actually in a particular place. For example, when planning a route, planning the complete route in advance using a map is often quite difficult. An alternative approach is to plan an ambiguous route in advance, and then picking specific roads by using road signs when one is driving.

In this way, tourist plans are often deliberately designed to be only as specific as necessary. A number of the tourists we interviewed talked about allocating days to particular places before they travelled. This sort of planning leaves a lot unspecified: when each day is, and what activities are done in each place, for example. Yet this sort of planning acknowledges that these sort of details are better kept flexible until closer to the time, as they will be dependent on local transport details, and can be adjusted in the face of other local contingencies, such as changing weather. Indeed, a stereotypical bad holiday is one that is excessively planned, in that changing circumstances are not be taken into account.

A second interesting aspect of tourist plans is how they follow or copy plans provided by others. A popular example of this is the package holiday, but even on package holidays not all of one's time is structured: many activities (such as choosing a restaurant) still involve some planning during the visit. For the tourists we followed, bus tours were frequently used to help structure the visit in this way. One group we followed took the tour bus on the first day they visited the city, so as to obtain an 'overview' of the city that they used on later days to organise the rest of their visit. While on the bus, one passenger drew a line on his map as the bus travelled around the city, letting him record where he had been for later recollection, and helping him to link the different sights together. In this way 
these bus tours had a role as an 'organising device' for a city visit, providing information about the key streets and attractions and allowing one to visit these again at leisure. The tours thus provided information and structure about the city, as much as being a strict plans or activity to follow in themselves.

If pre-visiting is about planning, then post-visiting is about reminiscing and sharing. Tourists often get together in groups to talk through their holidays, or to talk about their holidays to others who were not there (Frohlich et al., 2002). Photographs are very important for this activity in that they provide a framework around which stories can be told and experiences shared. Talking through the visit with photographs can take place both with those who were present on holiday and those who were not; in one form it is reminiscence, in another it allows the holiday to be shared. The combination of talk and interaction around pictures supports both these activities.

Post-visiting is thus a powerful way of extending the enjoyment of a tourist visit out beyond the visit itself. It also acts as a recommendation mechanism for different places - it allowing us to see 'what places are like' through our friends, and outside the commercially produced views of brochures and television (Crang, 1999). Indeed, some tourists who are on longer holidays go to the point of creating rich travelogues of their holiday, involving photographs, videos and text that are brought together to tell the story of their holiday. These travelogues usually exist in the form of photo albums, although a number of travelogues do exist on the Internet. However, there are considerable barriers to creating travelogues online-crafting web pages can take considerable time, and access to a PC and the Internet can be difficult while on holiday.

\section{Leisure and pleasure}

While we have described the experiences of tourists in terms of their 'problems' and 'solutions', we must not lose sight of the pleasurable nature of tourism, and how much of tourism involves activities that are not goal-oriented. That is to say, tourism is often nebulous with only tentative arrangements - we were struck by how the tourist experience was often not about finding the best restaurant, attraction or hotel, but in finding suitable attractions that allowed enjoyable experiences with travelling companions. These enjoyable experiences can range from the aesthetic (seeing a beautiful building), to the mundane (getting confused in a shop), to the social (spending time with a friend or family member whom one seldom sees). Tourism can thus be characterised as hedonic and emotional (Goosens, 2000), an experience typified by "wandering", where we attempt to enjoy the city environment and chance upon things of interest, rather than "optimising".

Learning how to design for these sorts of activities is one future challenge for $\mathrm{CSCW}$, as interest extends from worksites to other environments. Interfaces may succeed as much for their playful nature as their usability. The popularity of 
games like 'geo-caching' even suggests opportunities for threading games into the tourist experience. CSCW may have much to learn from games, in particular online games (Dyck et al., 2003) and games that interact with travellers' changing environments (Runnberg and Juhlin, 2003).

\section{Designing technologies for tourists}

Although tourism presents a number of barriers to introducing new technology in particular the need for devices to be sufficiently mobile - tourists have already adopted many new technologies, e.g. the web, mobile phones and digital cameras. This suggests that there are opportunities for new tourist systems that fit tourist practice. We now move on to discussing the implications from our study for designing better tourist technologies.

\section{Sharing the visit}

As emphasised above, an important part of tourism is sharing the visit with others. One problem that tourists face is co-ordinating their activities while they are separated-in particular getting groups back together again. One application that would assist this is a handheld or phone-based system that allowed tourists to communicate their locations to each other. So, if a group splits into two, they could choose to 'tie' their locations together so that each subgroup would be able to see where the other was. 'Tying' in this way could support synchronous awareness without running into difficult privacy problems. In addition, technology could support tourists showing the routes they took and things they did when they meet up again. This could allow them to make recommendations to their companions and also to other tourists whom they meet.

A second aspect of sharing visits is collaboration between tourists who do not know each other. One recommendation here is for technology to support sharing comments and reviews on different tourist attractions. However, it is important here to make this an interactive experience between tourists; as we discussed above, exchange of information is as much about meeting other tourists as it is exchanging information. This could be supported by using public machines or message walls where tourists can meet as they exchange information, or by enhancing existing sights where tourists meet, such as on city tours.

\section{Electronic guides and maps}

As discussed above, electronic guidebooks and maps have been a popular application area for mobile technology, with existing system generally following a similar format to paper guidebooks, augmented with GPS (for example TomTom CityMaps). Our fieldwork implies a number of limitations with this design. One innovation that electronic guidebooks could support is in making 
connections between where attractions are and what they are. Electronic guidebooks should explicitly support the comparison of information, allowing users to quickly move between related pieces of information. Partly due to the limited screen size, mobile systems seldom offer this feature. Pocket Internet Explorer, for example, only allows the user to load one web page at a time. One solution to this could be paper maps and electronic guidebooks that are designed to be used together. This would remove some of the disadvantages of the small screen by allowing users to juxtapose the PDA and the map in their visual field. More direct coupling is also feasible, e.g. through the PDA's sensing of printed glyphs and barcodes.

Mapping systems could also support more of the 'wandering' behaviour of tourists; for example, showing at a glance whether a tourist is going in the right direction rather than simply supporting a pre-determined route. Indicators could show nearby attractions, cafés, areas or main streets to support serendipitous discovery. This sort of representation moves beyond supporting wayfinding to supporting the broader range of tasks that tourists undertake when navigating. So, such a representation would support going between one shopping district and another, while looking for a café. In cases like this it is not the exact route that is important, although walking in the right direction is important, but a more general sense of learning about the city as one wanders around. Maps themselves could also show more of the 'social zoning' of different places, such as what areas are good for shopping, going out, or eating.

\section{Supporting pre and post- visiting}

Distinct from guidebooks, electronic tour guide systems attempt to offer information about a visitor's current location, and suggestions of where they might want to go next. These systems, such as the Lancaster GUIDE system, and more recently the EU funded "m-toGuide" system (http://www.mtoguide.org/), have generally been based around a 'walk-up pop-up' model where information (voice and text) is pushed at users based on their current location. Our observations suggest some limitations with this model. We observed that tourists frequently used maps and guides before visiting a place-an activity we call 'pre-visiting'. Presenting information to tourists while they are actually at an attraction may have limited utility, since at that point the environment is likely to contain richer sources of information than can be provided by a PDA. Our fieldwork also showed that tourists often do not follow tours in a straightforward way. Tours instead act as structures through which tourists can learn about the place being visited, and can use to build their own, more ad hoc plans. Systems should therefore present tours and attractions to tourists in such a way as to allow them to browse and learn from the tours rather than strictly following them, and to be aware of 'official' tourist attractions without being restricted to them. Viewing tours in advance would allow tourists to 'pre-visit' and judge different 
places and make their own plans about what to do rather than only following an official tour.

Lastly, our fieldwork emphasised the importance of post-visiting for tourists, allowing them to communicate and discuss their visit when they got home. We have been experimenting with support for this with the 'travelblog' system. This system allows tourists to build web-based travelogues describing their travels. These entries consist of pictures, videos and text captured on a Nokia 7650 camera-phone. These entries are then emailed from the phone to a server that automatically builds a web log combining the images and text. While some travelblogs are already on the Internet, created through increasingly popular weblogging software, our system also supports users replying to entries and having these messages forwarded via SMS to the tourist. Although this mechanism is very simple, it supports travellers updating their travelblog from anywhere in the world and extends the value of weblogs to the travelling tourist.

\section{Conclusion: Building technologies for leisure}

In this paper we have explored some important aspects of tourism, presenting an ethnographic study and design implications for tourist technologies. Using the metaphor of 'tourist problems' we explored the solutions that tourists use to arrange their visits. These solutions covered how tourists worked with other, used maps and guidebooks, and both pre- and post-visited places. We drew implications from this fieldwork for new technologies for tourists such as systems for remote co-visiting, and electronic guides and maps.

Designing technologies for tourists presents a number of specific challenges. Good tourist technologies are not only those that make tourists more efficient, but that also make tourism more enjoyable. As we discussed above, much of what is enjoyable about leisure is that it provides an opportunity to spend time with friends or family. In some senses, the leisure activity itself is less important than the fact that time is spent with significant others. Technologies that are woven into this sociality are likely to be used in preference to those that are not. Yet supporting sociality, sharing time and experiences together as part of friendships, may involve different technologies than those that support collaboration. One example of a system that does this is the Sotto Voce system, which allows visitors to an historic house to share a spoken commentary (Woodruff et al., 2001). The City project's system also addresses this, with support for co-visiting between groups of tourists and their friends at home.

In closing we would argue that support for leisure is both a new area of interest for CSCW and an area that is amenable to the methods and approaches developed in CSCW. As attention extends beyond the realm of work, and beyond technologies that support collaboration, it is the social aspect of leisure that may be the most important yet most challenging to support. 


\section{Acknowledgements}

We would like to thank Areti Galani and Eric Laurier for conversations around the issues discussed here. Ian MacColl helped build the travelblog system, and Jon Hindmarsh and Carl Gutwin gave useful comments on earlier drafts. We would also like to thank the very patient tourists who suffered our investigations, and to acknowledge our funding by the UK Engineering and Physical Sciences Research Council.

\section{References}

Abowd, G. D., et al. (1997): 'Cyberguide: A mobile context-aware tour guide', ACM Wireless Networks, vol. 3, no. 3, pp. 421-433.

Apostolopoulos, Y., et al., Eds. (1996): The sociology of tourism: theoretical and empirical investigations, Routledge.

Aramberri, J. (2001): 'The host should get lost: paradigms in tourism theory', Annals of Tourism Research, vol. 28, no. 3, pp. 738-761.

Bourdieu, P. (1990): Photography: a middlebrow art, Polity Press, London.

Brown, B., et al. (2001): 'Music sharing as a computer supported collaborative application', in W. Prinz (Ed.) Proceedings of ECSCW 2001. Bonn, Kluwer, pp. 179-198.

Brown, B., et al. (2003): 'Lessons from the Lighthouse: Collaboration in a shared mixed reality system', in Proceedings of CHI 2003. Fort Lauderdale, ACM Press, pp. 577-584.

Chalmers, M. (2003): 'Awareness, representation and interpretation', J. CSCW, vol. 11, no. 3-4, pp. 389-409.

Cheverst, K., et al. (2000): 'Developing a Context-aware Electronic Tourist Guide: Some Issues and Experiences', in Proceedings of CHI 2000. The Hague, ACM Press, pp. 17-24.

Cornell, E. H. and C. D. Heth (2000): 'Route learning and navigation', in R. Kitchin and S. Freundschuh (Eds.): Cognitive mapping: past, present and future. Routledge, pp. 66-83.

Crabtree, A. (1999): The tourist information centre study: eSCAPE Deliverable 4.2, The Tourist Physical Electronic Landscape Demonstrator: 3-12. http://www.mrl.nott.ac.uk/ axc/PDF/eSCAPE\%20D4.2.pdf.

Crang, M. (1999): 'Knowing, tourism and the practices of vision', in D. Crouch (Ed.) Leisure/tourism geographies: practices and geographical knowledge. London, Routledge, pp. 238-256.

De Certeau, M. (1984): The practice of everyday life, University of California Press, Berkeley.

Dyck, J., et al. (2003): 'Learning from Games: HCI Design Innovations in Entertainment Software'. To appear in Proceedings of Graphics Interface 2003.

Fesenmaier, D., et al., Eds. (2000): Information and communication technologies in tourism, Springer.

Fodness, D. and B. Murry (1997): 'Tourist information search', Annals of Tourism Research, vol. 24, no. 3, pp. 503-523.

Frohlich, D. M., et al. (2002): 'Requirements for photoware', in Proceedings of CSCW '02. New York, ACM Press.

Goosens, C. (2000): 'Tourist information and pleasure motivation', Annals of Tourism Research, vol. 27 , no. 3, pp. 301-321.

Grinter, R. E. and M. Eldridge (2001): 'y do tngrs luv 2 txt msg?', Proceedings of ECSCW 2001. Bonn, Kluwer, pp. 219-238. 
Hughes, J., et al. (2000): 'Patterns of Home Life: Informing Design For Domestic Environments', Personal Technologies (Handheld and Ubiquitous Computing), vol. 4, no. 3, pp. 11-39.

Hunt, E. and D. Waller (1999): Orientation and wayfinding: A review, ONR technical report N00014-96-0380. Arlington, VA, Office of Naval Research.

Jonsson, E. (2002): Inner Navigation, Scribner.

Lee, J. R. E. and D. R. Watson (1993): Final Report to the Plan Urbain: Public Space as an Interactional Order. Manchester, Department of Sociology, University of Manchester.

Lloyd, R. (1989): 'Cognitive maps: encoding and decoding information', Annals of the Association of American Geographers, vol. 79, no. 3, pp. 101-124.

Loker-Murphy, L. and P. L. Pearce (1995): 'Young budget travellers: backpackers in Australia', Annals of Tourism Research, vol. 22, no. 3, pp. 819-843.

MacEachren, A. M. (1995): How maps work, Guilford Press, New York.

Moore, K., et al. (1995): 'Behavioural conceptualization of tourism and leisure', Annals of Tourism Research, vol. 22, no. 3, pp. 67-85.

Munro, A. (1998): Fringe benefits: an ethnographic study of social navigation at the Edinburgh Festival. Stockholm, Sweden, SICS, Persona deliverable 2.1.1.

Pearce, D. (1995): Tourism today: a geographical analysis, Longman Scientific \& Technical, Harlow.

Riley, R. and L. Love (1999): 'The state of qualitative tourism research', Annals of Tourism Research, vol. 27, no. 3, pp. 164-187.

Runnberg, L. and O. Juhlin (2003): 'Movement and Spatiality in a Gaming Situation - Boosting Mobile Computer Games with the Highway Experience'. To appear in: Proceedings of Interact 2003.

Sacks, H. (1992): Lectures on conversation, Basil Blackwell, Oxford.

Schlegoff, E. (1972): 'Notes on a conversational practice: Formulating place', in D. Sudnow (Ed.) Studies in Social Interaction. New York, Free Press, pp. 75-119.

Schmidt, K. (1997): 'Of maps and scripts: The status of formal constructs in cooperative work', in Proceedings of Group'97. Phoenix, ACM Press, pp. 138-147.

Sellen, A. and R. Harper (2001): The myth of the paperless office, MIT Press.

Simon, H. A. (1955): 'A Behavioural Model of Rational Choice', Quarterly Journal of Economics, vol. 69 , no. 3 , pp. $99-118$.

Smith, D. E. (1996): 'Telling the truth after postmodernism', Symbolic Interaction, vol. 19, no. 3, pp. 171-202.

Snepenger, D. J., et al. (1990): 'Information search strategies by destination-naive tourists', Journal of Travel Research, vol. 29, no. 3, pp. 13-16.

Star-UK (2000): United Kingdom Tourism Survey. London, UK, Star UK - statistics on tourism and research. http://www.staruk.org.uk//default.asp?ID=468\&parentid=469.

Suchman, L. (1987): Plans and situated actions: The problem of human-machine communication, Cambridge University Press, Cambridge.

Tribe, J. (1999): Economics of Leisure and Tourism, Butterworth-Heinemann, London.

Urry, J. (1995): Consuming Places, Routledge, London.

USDTI (1999): Survey of international air travelers: Profile of Overseas Travellers to the U.S, US department for Tourism Industries. http://www.tinet.ita.doc.gov/view/f-1999-07-001/.

vom Lehn, D., et al. (2001): 'Exhibiting Interaction: Conduct and Collaboration in Museums and Galleries', Symbolic Interaction, vol. 24, no. 3, pp. 189-216.

Woodruff, A., et al. (2001): 'Electronic Guidebooks and Visitor Attention' in Proc. 6th Int'l Cultural Heritage Informatics Meeting. Archives and Museum Informatics, pp. 437-454. 